\title{
REVIEW
}

\section{Chromosome analysis: what and when to request}

\author{
F H Sharkey, E Maher, D R FitzPatrick
}

Arch Dis Child 2005;90:1264-1269. doi: 10.1136/adc.2004.068668

Chromosome abnormalities have long been recognised as an important cause of learning disability and multiple malformation syndromes; $0.8 \%$ of live born infants have numerical or structural chromosomal anomalies resulting in an abnormal phenotype. The identification of such anomalies is important, both clinically and for accurate genetic counselling. Recently, the human genome sequence has enabled higher resolution screens for chromosome anomalies using both molecular cytogenetic and array based techniques. This review suggests a simple algorithm for the targeted use of diagnostic cytogenetic tools in specific patient groups commonly seen in paediatric practice.

See end of article for authors' affiliations

Correspondence to: Dr D R FitzPatrick, MRC Human Genetics Unit, Edinburgh EH4 2XU, UK; david.fitzpatrick@hgu.mrc. ac.uk

Accepted 26 August 2005
C linical geneticists are notorious jargon users and clinic letters or consult notes conclude with a statement to the effect that no specific syndrome diagnosis can be made but the child looks very "chromosomal". This unusual adjective refers to a collection of clinical features that predict an increased likelihood of finding a cytogenetic abnormality on routine testing. These include:

- Congenital, global delay in neurocognitive development

- One or more major malformations

- Prenatal onset abnormal growth pattern

- Craniofacial dysmorphisms

- Unusual behavioural phenotypes, often in the autistic spectrum

- Abnormal dermatoglyphic (finger and palm epidermal ridges) or trichoglyphic (scalp hair boundaries and hair growth trajectory) pattern

- A family history of multiple miscarriages, learning disability, or malformations.

Unfortunately, no positive predictive value exists for any aspect of the "chromosomal" impression, although attempts to formalise this are beginning to appear. ${ }^{1}$

About $0.8 \%$ of live born children have chromosomal anomalies (table 1) and half of these individuals have an abnormal phenotype. ${ }^{2}$ The best predictor of deleterious phenotypic consequence is the gain or loss of chromosomal material, which is termed aneuploidy. Chromosomal anomalies are categorised as:

- Numerical (gain or loss of whole chromosomes), e.g. Down's syndrome, caused by trisomy of chromosome 21, with a birth incidence of about 1 in 800-1000
- Structural (large scale abnormalities in genomic sequence of individual chromosomes). These may be balanced (where genomic material is rearranged but not gained or lost) or unbalanced (results in aneuploidy) (fig 1).

Conventional cytogenetic analysis uses light microscopy to examine metaphase or prometaphase chromosomes that have been stained to produce a distinct banding pattern for each chromosome. This approach has a maximum resolution of 3-5 megabases $(\mathrm{Mb})$ for structural anomalies $^{34}$ and requires dividing cells, usually peripheral blood leucocytes, bone marrow, or fibroblasts, for analysis. Fluorescent in situ hybridisation (FISH) analysis uses labelled DNA probes to identify submicroscopic (or cryptic) structural chromosome anomaliesmicrodeletions and microduplications.

Comparative genomic hybridisation microarray technology provides a diagnostic method for systematic and comprehensive analysis of human aneuploidy (fig 2). Array-CGH provides much higher resolution (currently up to 100$200 \mathrm{~kb}$ ) and has great potential for automation. Array-CGH is now being applied to human malformation syndromes and cohorts with learning disabilities, ${ }^{5-7}$ providing higher resolution definition of known structural aberrations and detecting aneuploidy that was undetected by FISH or chromosome banding techniques. ${ }^{8}{ }^{9}$

This review will discuss the clinical utility of each of the techniques mentioned above as diagnostic and research tools in paediatrics, and their applicability to specific patient groups.

\section{POPULATION BASED STUDIES}

In the 1960s and 1970s cytogenetic screens of unselected newborns in the "pre-banding" era showed and overall birth prevalence of $0.56 \%$ $(1: 178)^{10}$ with numerical and structural chromosomal abnormalities contributing $0.33 \%$ and $0.22 \%$ respectively (table 1 ). A later study using moderate level banding (400-500) found the respective frequencies of balanced and unbalanced structural abnormalities to be $0.522 \%$ and $0.061 \%$. Such moderate banding increases the overall frequency of abnormalities detectable in the newborn to $0.917 \% .{ }^{11}$ Large scale newborn screens are not available using molecular cytogenetic or array-CGH techniques and the ethical complexities and cost implications of such studies make it unlikely that these will be attempted in the future.

\section{RECOGNISABLE CHROMOSOMAL SYNDROMES}

Since the advent of clinical cytogenetic analysis it has been recognised that chromosomal deletions 
Table 1 Chromosome anomalies detected using conventional cytogenetics in newborn screens

\begin{tabular}{lclll}
\hline & & \multicolumn{2}{l}{ Rearrangements } & \\
\cline { 3 - 4 } Reference & Sample no. & Structural & Numerical & Detection rate (\%) \\
\hline Jacobs et al, 1992 & 14677 & 112 & NC & 0.7 \\
Hansteen et al, 1982 & 1830 & 25 & 11 & 1.9 \\
Hamerton et al, 1975 & $46150^{*}$ & 103 & 155 & 0.56 \\
\hline
\end{tabular}

NC, not considered in this study.

*Data from six studies reviewed by authors in addition to their own data using conventional staining methods.

and duplications, like autosomal trisomies, can produce recognisable syndromes. There is an increasing number of such syndromes, but two of the best known are deletion (del) of the distal short arm of chromosome $4(\operatorname{del}(4)(\mathrm{pl} 6)$, a.k.a. $4 \mathrm{p}-)$, which results in Wolf-Hirchhorn syndrome, and $\operatorname{del}(5)($ pl3->pl5) (a.k.a. 5p-), which causes Cri du Chat. A puzzling group of children who had convincing clinical features of these syndromes but normal chromosomes using conventional analysis were explained with the ability to identify microdeletions using molecular cytogenetics. Many different microdeletion syndromes are now recognised and most, like Williams syndrome $(\operatorname{del}(7)(q 11.2)$ ish), are truly cryptic and are only detectable by FISH and such technologies. The speedy diagnosis of such conditions requires the referring clinician to request specific FISH analysis (tables 3 and 4). This is now a common role for the paediatric geneticist or dysmorphologist.

\section{LEARNING DISABILITY/MENTAL RETARDATION (LD/MR)}

The reported detection rates for different cytogenetic approaches to learning disability are summarised in table 2 . These studies are plagued with inconsistencies in definition, severity, patient selection criteria (for example, outpatient clinic, institutional population), sample size, presence/ absence of congenital anomalies, rigour of syndromic assessment, and assay specifications. In a review of nine screening studies by van Karnebeek and colleagues, ${ }^{12}$ chromosome banding techniques were shown to have a detection rate of $13.3 \%(3.8 \%$ structural $/ 7.8 \%$ numerical rearrangements) in moderate-severe $\mathrm{LD} / \mathrm{MR}$ cases (IQ score $<50$ ) and $4.1 \%$ for mild-moderate cases (IQ 50-70). The equivalent detection rate for subtelomere FISH screens in four studies reviewed was $6.7 \%$ for moderate-severe LD cases and $0.5 \%$ for mild-moderate $\mathrm{LD}$. The recommendation of this

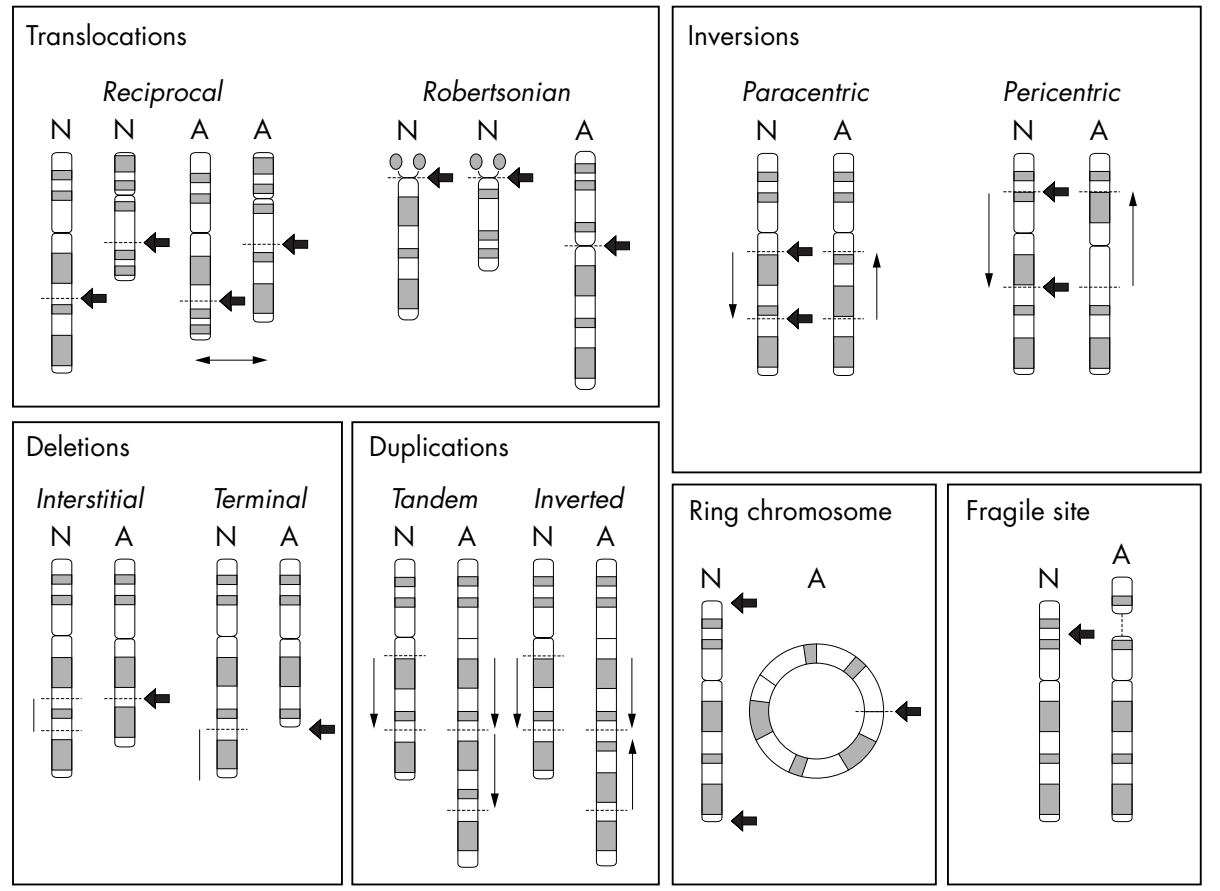

Figure 1 Common structural anomalies in clinical cytogenetics: various categories of structural anomalies are reported in clinical cytogenetics. Among the most common are translocations (top panel, left side) which may be reciprocal (a swap of chromosome material between non-homologous chromosomes) or Robertsonian (a fusion of two acrocentric chromosomes). Translocations are further classified into whether they are balanced (no apparent gain or loss of chromosomal material) or unbalanced (rearrangement results in aneuploidy). Inversions (top panel, right side) are where the normal order of genomic material within a chromosome is altered by the abnormal repair of chromosomal breakpoints (block arrows and dotted lines). If the inversions include the centromere of the chromosome they are called pericentric, if not, paracentric. Deletions (bottom panel, far left) and duplications (bottom panel, second left) are structural rearrangements causing loss or gain, respectively, of part of a chromosome. Ring chromosomes (bottom panel, second right) are caused by fusion of the ends of chromosomes. Fragile sites (bottom panel, right hand side) are apparent gaps in chromosomes. These may be due to expansion of small repeats in DNA. The best known pathological example of this is a marker of the fragile $\mathrm{X}$ syndrome at Xq27.3. 
Table 2 Application of subtelomere FISH, conventional cytogenetic techniques, and array-CGH for the detection of chromosomal abnormalities involved in LD/MR

\begin{tabular}{|c|c|c|c|c|c|c|}
\hline \multirow{2}{*}{$\begin{array}{l}\text { Level of } \\
\text { LD/MR }\end{array}$} & \multirow[b]{2}{*}{ Method } & \multirow[b]{2}{*}{ Sample no. } & \multicolumn{2}{|c|}{ Rearrangements } & \multirow{2}{*}{$\begin{array}{l}\text { Detection rate } \\
\text { (\%) }\end{array}$} & \multirow[b]{2}{*}{ Reference } \\
\hline & & & Structural & Numerical & & \\
\hline \multirow[t]{10}{*}{ Mild-moderate } & Subtelomere FISH & & & & & \\
\hline & Multiprobe FISH & 182 & 1 & & 0.5 & Knight et $a l^{15}$ \\
\hline & Multiprobe FISH & 103 & 1 & & 1.0 & Van Karnebeek et $a^{24}$ \\
\hline & Multiprobe FISH & 40 & 4 & & 10.0 & Dawson et $a l^{13}$ \\
\hline & Various & 4 studies & NR & NR & 0.5 & Van Karnebeek et $a l^{12}$ \\
\hline & & 44 & $1 \%$ & $3 \%$ & & \\
\hline & Conventional cytogenetics & & & & & \\
\hline & Various & 5 studies & & & 0.0 & Rossi et $a P^{5}$ \\
\hline & 400-550 chromosome banding & 200 & & & 4.1 & Van Karnebeek et $a l^{2}$ \\
\hline & Array-CGH & N/A & & & 4.1 & Rossi et $a f^{25}$ \\
\hline \multirow{10}{*}{$\begin{array}{l}\text { Moderate- } \\
\text { severe }\end{array}$} & Subtelomere FISH & & & & & \\
\hline & Multiprobe FISH & 284 & 21 & & 7.4 & Knight et $a l^{15}$ \\
\hline & Multiprobe FISH & 254 & 13 & & 5.1 & Riegel et $a^{26}$ \\
\hline & Multiprobe FISH & 81 & 0 & & 0.0 & Van Karnebeek et $a f^{24}$ \\
\hline & Multiprobe FISH & 117 & 12 & & 10.2 & Rossi et $a^{25}$ \\
\hline & $\begin{array}{l}\text { Various } \\
\text { Conventional cytogenetics }\end{array}$ & 4 studies & NR & NR & 6.7 & Van Karnebeek et $a l^{2}$ \\
\hline & Various & 9 studies & $3.8 \%$ & $7.8 \%$ & 13.3 & Van Karnebeek et $a l^{2}$ \\
\hline & Array-CGH & & & & & \\
\hline & $1 \mathrm{Mb} \mathrm{BAC} / \mathrm{PAC}$ array & 50 & 12 & & 24 & Shaw-Smith et al \\
\hline & $1 \mathrm{Mb} B A C / P A C$ array & 20 & 4 & & 20 & Vissers et aP \\
\hline
\end{tabular}

review was to use standard karyotyping as a first line test. High resolution chromosome banding has been reported to have an overall detection rate of $7.5 \%$ for anomalies in patients with mild-moderate and moderate-severe LD/ $M{ }^{12}{ }^{13}$ although there are various reports documenting much lower detection/prevalence rates. ${ }^{14} 15$
The specialised regions at the ends of all chromosomes are called telomeres. The adjacent subtelomeric regions of the genome are gene-rich and are susceptible to abnormal chromosomal rearrangements during meiosis. This has led to various FISH based diagnostic strategies being developed to detect such rearrangements. PCR quantitation and more
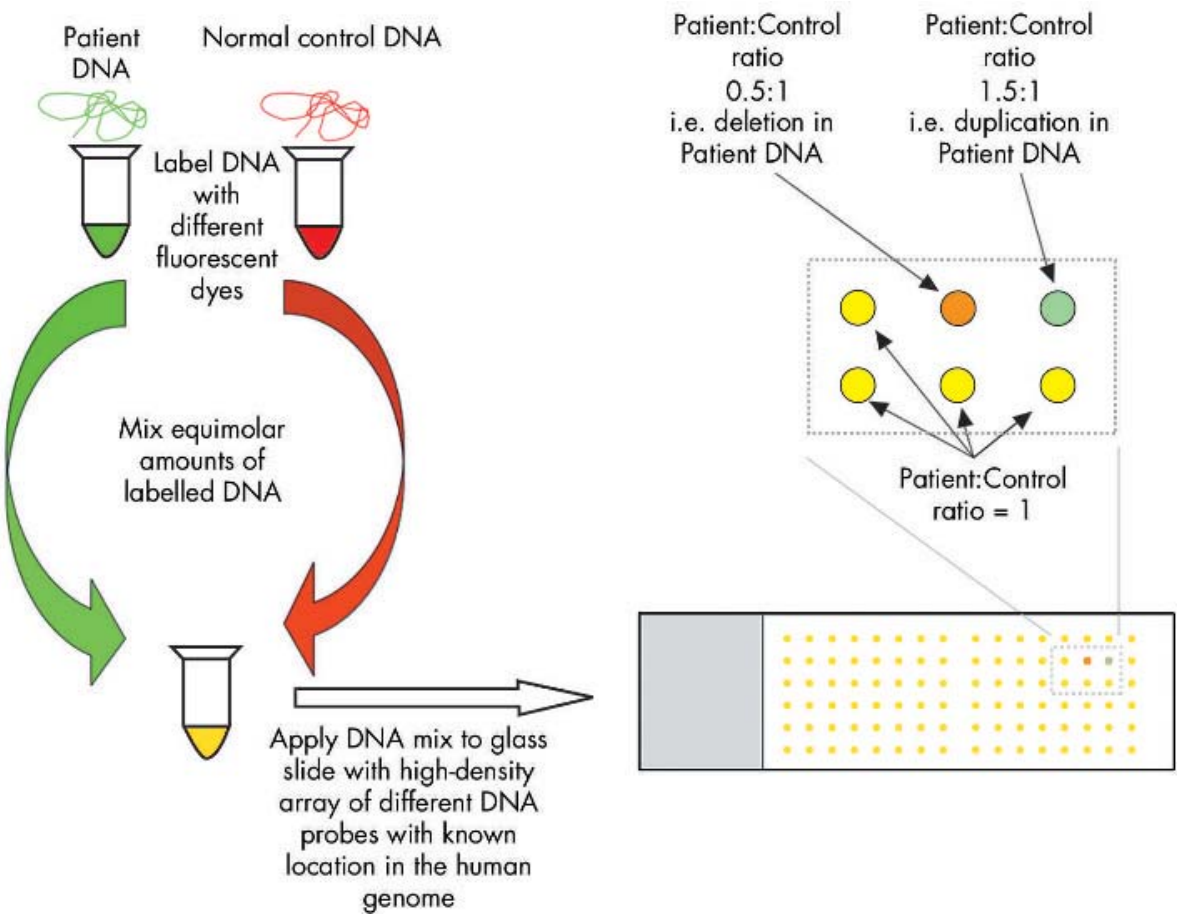

Figure 2 Array-CGH analysis: a test and a normal control DNA are labelled with different fluorochromes (in the figure, test is green, normal is red) and co-hybridised to a microarray containing DNA clones whose position in the human genome is known. The resolution of the analysis is dictated both by the size of the DNA clones and the size of the gap between the clones. The most commonly used arrays contain 3000-4000 clones of 200000 base pairs in size spaced at 1000000 base pair intervals throughout the genome. Digitised intensity differences in the hybridisation patterns between the test/normal samples onto these cloned fragments can be interpreted as copy number change(s) at that position(s). For example, if the hybridisation is equal between tester and control DNA the red/green fluorochrome signal mix will give a yellow colour. If the test DNA contains a deletion, then red $>$ green and an orange colour will result. If the test DNA contains a duplication, the green fluorochrome will be more abundant than the red. 


\begin{tabular}{|c|c|c|c|c|}
\hline Locus & Syndrome & Incidence & Major gene & Clinical features \\
\hline $22 q 11.2$ & $\begin{array}{l}\text { Di George, velocardiofacial, } \\
\text { conotruncal facial anomaly }\end{array}$ & 1 in 4000 & $\begin{array}{l}\text { TBX1 (cardiac defects } \\
\text { and cleft palate) }\end{array}$ & $\begin{array}{l}\text { Cardiac oufflow tract defects, distinctive facial } \\
\text { appearance, thymic hypoplasia, cleft palate, and } \\
\text { hypocalcaemia }\end{array}$ \\
\hline $15 q 11-q 13$ & Prader-Willi & 1:15000 & $\begin{array}{l}\text { Imprinted region, deletions on } \\
\text { paternal allele in } 70 \% \text { cases }\end{array}$ & $\begin{array}{l}\text { Distinctive facial appearance, hyperphagia, small hands } \\
\text { and feet, distinct behavioural phenotype }\end{array}$ \\
\hline $15 q 11-q 13$ & Angelman & $1: 15000$ & $\begin{array}{l}\text { Imprinted region, deletions on } \\
\text { maternal allele in UBE3A }\end{array}$ & $\begin{array}{l}\text { Distinctive facial appearance, absent speech, EEG } \\
\text { abnormality, characteristic gait }\end{array}$ \\
\hline $7 q 11.23$ & Williams & $1: 10000$ & $\begin{array}{l}\text { Elastin (supravalvular aortic } \\
\text { stenosis) }\end{array}$ & $\begin{array}{l}\text { Distinctive facial appearance, supravalvular aortic } \\
\text { stenosis, learning disability, and infantile } \\
\text { hypercalcaemia }\end{array}$ \\
\hline $17 p 11.2$ & Smith-Magenis & 1 in 25000 & RAl1 & $\begin{array}{l}\text { Distinctive facial appearance and behavioural } \\
\text { phenotype, self-injury, and REM sleep abnormalities }\end{array}$ \\
\hline $17 p 11.3$ & Miller-Dieker & Rare & LISI and 14-3-3 & $\begin{array}{l}\text { Distinctive facial appearance, lissencephaly, severe } \\
\text { learning disability, heart defects, growth retardation, } \\
\text { and seizures }\end{array}$ \\
\hline $5 p 15$ & Cri du Chat & Rare & Unknown & $\begin{array}{l}\text { Microcephaly, micrognathia, epicanthic folds, and high } \\
\text { pitched cry }\end{array}$ \\
\hline $13 q 14$ & Retinoblastoma & Rare & $\mathrm{RB} 1$ & Retinoblastoma, learning disability \\
\hline $16 p 13.3$ & Rubinstein-Taybi & Rare & $\begin{array}{l}\text { CREB deletions account for } \\
<10 \% \text { of cases }\end{array}$ & $\begin{array}{l}\text { Distinctive facial appearance, short stature, broad } \\
\text { thumbs }\end{array}$ \\
\hline $4 \mathrm{p} 16.3$ & Wolf-Hirschhorn & Rare & WHSCl & $\begin{array}{l}\text { Distinctive facial appearance, seizures, short stature, cleft } \\
\text { lip, coloboma }\end{array}$ \\
\hline $11 \mathrm{p} 13$ & WAGR & Rare & PAX6, WTI & $\begin{array}{l}\text { Aniridia, Wilms' tumour, male genital tract } \\
\text { malformations, learning disability }\end{array}$ \\
\hline
\end{tabular}

recently array based comparative genomic hybridisation (array-CGH) can also detect the same anomalies (fig 2). Cryptic subtelomeric chromosomal anomalies may cause either specific (table 4) or non-specific phenotypes such as "idiopathic" learning disability/mental retardation (LD/MR) with or without craniofacial dysmorphism. ${ }^{13}$

Subtelomeric FISH can detect cryptic deletions and balanced or unbalanced translocations. Probes must be chosen carefully as subtelomeric regions are complex and can cross-hybridise (for example, $8 p$ with $1 p$ and $3 q$ ) and show polymorphic deletions (for example, 2q). ${ }^{14}{ }^{15}$ Family studies are critical for interpretation of positive FISH results. There is extreme variability in the reported prevalence of subtelomere rearrangements in patients with LD/MR. However, subtelomeric rearrangements may be the second most common cause of LD/MR in children after Down's syndrome, with an overall detection rate of $5.1 \% \mathrm{LD} / \mathrm{MR}{ }^{16}$ The reported detection rates using subtelomere FISH in moderate-severe LD/MR patients are, as would be expected, higher than those in mild-moderate groups (table 2). A five point checklist has been developed to facilitate preselection for subtelomeric screening and increase diagnostic detection rates in patients with LD/MR. The checklist includes family history of LD/MR, prenatal onset growth retardation, postnatal growth abnormalities, $\geqslant 2$ facial dysmorphic features, and one or more non-facial dysmorphic feature(s) and/or with congenital abnormalities. ${ }^{1}$

Array-CGH (fig 2) holds great promise for the detection of chromosomal anomalies in children with LD/MR. Using an array where the clones were targeted to the subtelomeric region, a blinded study of 20 patients with unclassified MR and/or with multiple congenital anomalies, all subtelomeric abnormalities detected by FISH were correctly identified by array-CGH; this technique also identified rearrangements in an additional three patients missed by FISH. ${ }^{9}$ A whole genome based DNA microarray with a resolution of approximately one clone per megabase has been used to investigate 50 patients presenting with moderate to severe learning difficulties of unknown cause. ${ }^{6}$ All patients showed normal $\mathrm{G}$ banded karyotypes, with one exception, and in $82 \%$ of patients, subtelomeric rearrangements were excluded by FISH and genotyping. A loss or gain of genetic material was detected in 12 patients (seven deletions and five duplications), giving a rearrangement detection rate of $24 \%$. Another recent study has shown a similar rate of cryptic aneuploidy in patients with moderate-severe LD/MR. ${ }^{7}$ The patients in these studies were selected on the basis of a phenotype suggestive of a chromosome anomaly and thus may not be representative of all patients within the MR category. Two of the genomic abnormalities were also found in a normal parent, suggesting that these may be copy number polymorphisms ${ }^{7}$ and emphasising the need for sufficient normal control data before this technique can be used in routine clinical analysis. Array-CGH has also been successfully used to analyse patients, with an abnormal phenotype and LD/MR, but carrying apparently balanced de novo translocations. ${ }^{27}$ Abnormal phenotypes in patients with apparently balanced de novo translocations are thought to result from gene dosage alterations at the breakpoints or by microdeletions/ duplications. Additional rearrangement complexity at the breakpoints in balanced cases were detected using high resolution microarrays, with unsuspected cryptic imbalances detected in one third of the patients involving chromosomes that were not directly related to their de novo translocations.

Table 4 Recognised syndromes associated with subtelomeric deletions

\begin{tabular}{ll}
\hline Locus & Clinical features \\
\hline $1 p 36$ & Distinctive facies, seizure, sensorineural hearing loss, cardiomyopathy, learning disability \\
$2 q 37$ & Partial phenocopy of Albright hereditary osteodystrophy, learning disability \\
$9 q 34$ & Midface hypoplasia, learning disability, conotruncal defects, hypotonia, obesity \\
$22 q 13$ & Severe speech and language delay and autistic-like behaviour, learning disability \\
\hline
\end{tabular}



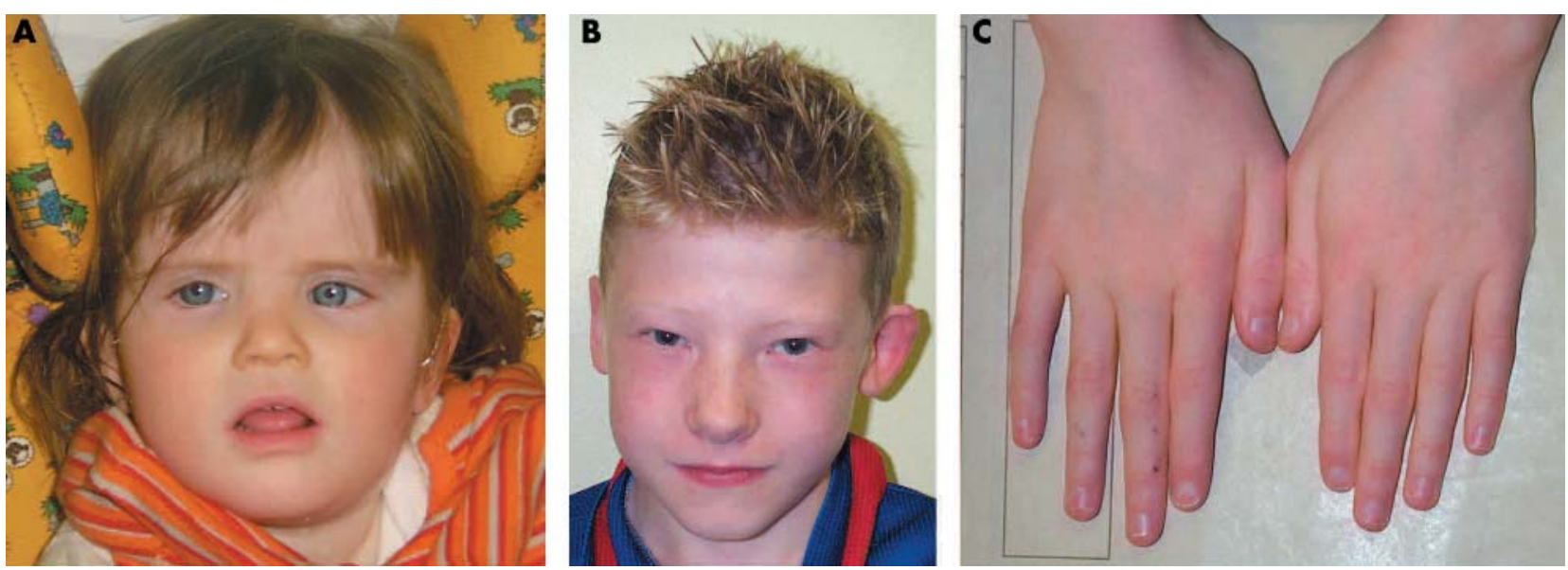

Figure 3 Facial photographs of patients with clinically recognisable chromosome abnormalities. (A) 1.5 year old girl with typical facial appearance of 1 p36 deletion: note straight eyebrows, deep-set eyes, small mouth with short philtrum. A hearing aid is visible as hearing loss is common in this condition. This girl also has a severe seizure disorder, prenatal onset growth failure, and learning disability. (B) 13 year old boy with del(22)(q1 1.2) microdeletion syndrome. He has upslanting palpebral fissures, a broad nasal bridge, and a small mouth. (C) Hands of the same boy showing characteristic long slim digits. He also had tetralogy of Fallot and speech delay. He is now doing well at normal school with learning support. Parental consent was obtained for publication of the children in this figure.

\section{CONGENITAL MALFORMATIONS}

Unfortunately, there are few systematic studies of chromosome anomalies in large cohorts with specific congenital malformations. Much of the available diagnostic information on malformations comes from fetal chromosome analysis following abnormal prenatal ultrasound findings. ${ }^{17}$ Interpretation of the available data in paediatric populations is difficult as many of malformation cases investigated also have LD/MR. Array-CGH has particular promise in diagnosis of malformations and syndrome entities. For example, in a pilot study of 22 patients with iris hypoplasia (6p25 segmental duplication) and Axenfeld-Rieger syndrome (6p25 segmental deletion), ${ }^{5}$ all samples was correctly identified by array-CGH (10 duplications, two deletions, and seven normals). Another study using CGH arrays has established a critical candidate region of $5 \mathrm{Mb}$ exists on $18 \mathrm{q} 22.3-18 \mathrm{q} 23$ for patients with congenital aural atresia (CAA), and narrowing or absence of the middle ear. ${ }^{9}$ Further studies will inevitably narrow this region more specifically. Campomelic dysplasia (CD) syndrome is a rare, sporadic, autosomal dominant skeletal dysplasia marked by bowed long bones in the limbs, severe respiratory distress, and reversed sex in some male patients. Most CD cases have heterozygous de novo mutations in the coding region of SOX9. Array-CGH detected two deletions in 11 CD patients, the first being a de novo deletion of approximately $4 \mathrm{Mb}$ that included the SOX9 locus. The other deletion knocked out two evolutionary conserved regulatory elements $5^{\prime}$ to SOX9.18 $\mathrm{CGH}$ has also recently been used to determine gene copy number in other well known genomic disorders including

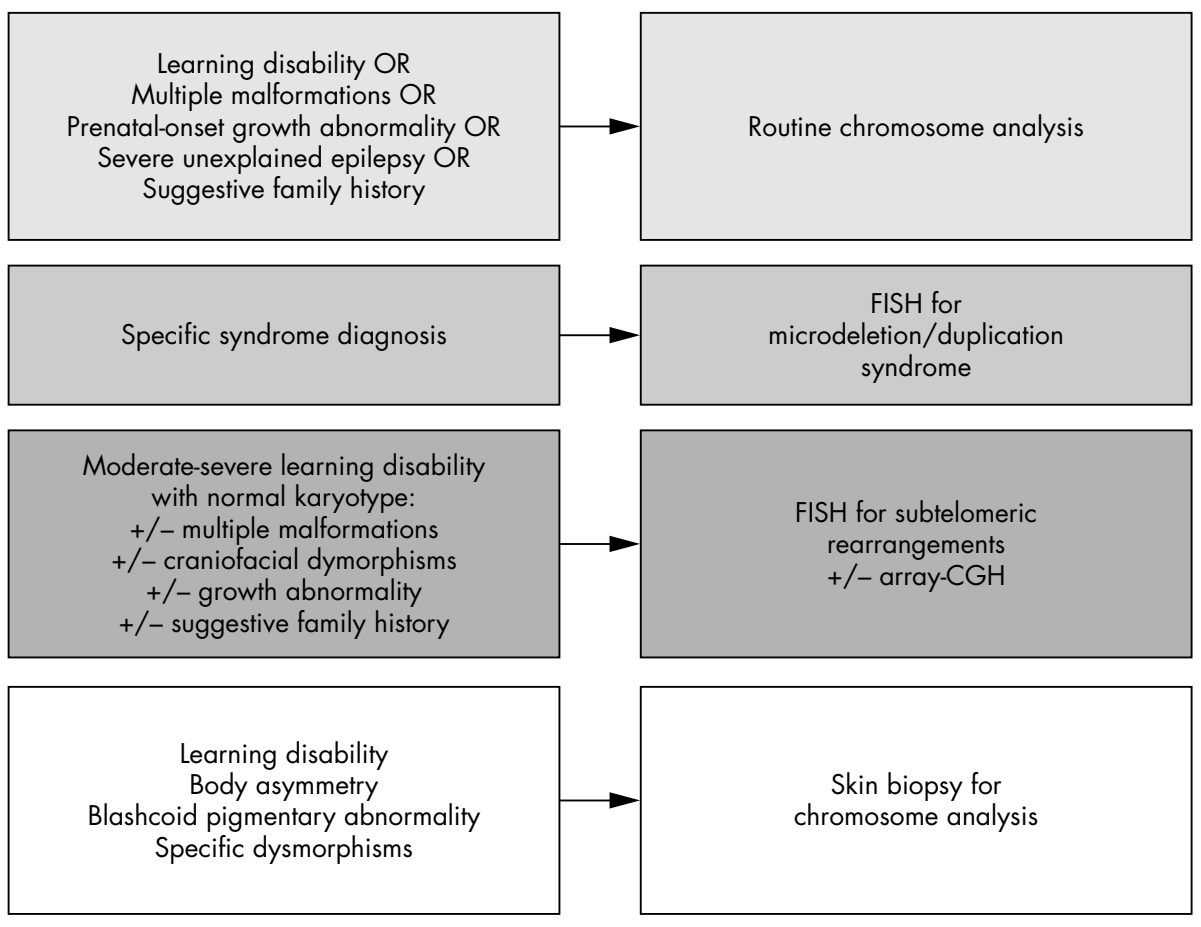

Figure 4 Summary of the main reasons for referral for specific cytogenetic investigations. enatal-onset growth abnormality $O R$ vere unexplained epilepsy OR Suggestive family history

pecific syndrome diagnosis

derate-severe learning disability

- craniofacial dymorphism

+ - growth abnormality

+ /- suggestive family history

Learning disability Body asymmetry

Specific dysmorphisms chromosome analysis 
Smith Magenis, Charcot-Marie-Tooth disease type IA, hereditary neuropathy and $\operatorname{dup}(17)(\mathrm{pl} 1.2 \mathrm{pl} 1.2),{ }^{19} \quad$ WolfHirschhorn syndrome, ${ }^{20}$ and cardio-facio-cutaneous syndrome. ${ }^{21}$

\section{FUTURE PERSPECTIVES AND RECOMMENDATIONS}

Array-CGH is a sensitive, flexible, and automatable technique that is likely to revolutionise paediatric genetic investigations over the next five years. It is already in routine use in cancer diagnostics, prognosis, and therapeutic choices. ${ }^{22}$ Array technologies are not without inherent limitations; they do not provide information on the precise location of the rearranged sequences responsible for the copy change(s). The currently available whole genome slides are currently too expensive to apply to routine clinical referrals. For now conventional cytogenetics $+/-$ FISH remains the mainstay of clinical cytogenetic investigation. A simple summary of appropriate referrals for clinical cytogenetic analysis is given in fig 4. This is likely to change, and it is important that paediatricians maintain close contact with their colleagues in clinical genetics to ensure that appropriate genetic investigations are carried out in common clinical situations.

\section{Authors' affiliations}

F H Sharkey, D R FitzPatrick, MRC Human Genetics Unit, Edinburgh, UK E Maher, Regional Cytogenetics Service, Western General Hospital, Edinburgh, UK

Competing interests: none declared

Parental consent was obtained for publication of the children in figure 3

\section{REFERENCES}

1 de Vries BB, White SM, Knight SJ, et al. Clinical studies on submicroscopic subtelomeric rearrangements: a checklist. J Med Genet 2001;38:145-50.

2 Gardner RJM, Sutherland GR. Chromosome abnormalities and genetic counselling. New York: Oxford University Press, 1996.

3 De Vries BB, Winter R, Schinzel A, et al. Telomeres: a diagnosis at the end of the chromosomes. J Med Genet 2003;40:385-98.

4 Salman M, Jhanwar SC, Ostrer H. Will the new cytogenetics replace the old cytogenetics? Clin Genet 2004;66:265-75.

5 Ekong R, Jeremiah S, Judah D, et al. Chromosomal anomalies on $6 \mathrm{p} 25$ in iris hypoplasia and Axenfeld-Rieger syndrome patients defined on a purpose-built genomic microarray. Hum Mutat 2004;24:76-85.

6 Shaw-Smith C, Redon R, Rickman L, et al. Microarray based comparative genomic hybridisation (array-CGH) detects submicroscopic chromosomal deletions and duplications in patients with learning disability/mental retardation and dysmorphic features. J Med Genet 2004;41:241-8. 7 Vissers LE, de Vries BB, Osoegawa K, et al. Array-based comparative genomic hybridization for the genomewide detection of submicroscopic chromosomal abnormalities. Am J Hum Genet 2003;73:1261-70.

8 Albertson DG, Pinkel D. Genomic microarrays in human genetic disease and cancer. Hum Mol Genet 2003;12:R145-52.

9 Veltman JA, Schoenmakers EF, Eussen BH, et al. High-throughput analysis of subtelomeric chromosome rearrangements by use of array-based comparative genomic hybridization. Am J Hum Genet 2002;70:1269-76.

10 Hamerton JL, Canning N, Ray M, Smith S. A cytogenetic survey of 14,069 newborn infants. I. Incidence of chromosome abnormalities. Clin Genet 1975;8:223-43.

11 Jacobs PA, Browne C, Gregson N, et al. Estimates of the frequency of chromosome abnormalities detectable in unselected newborns using moderate levels of banding. J Med Genet 1992;29:103-8.

12 van Karnebeek CD, Jansweijer MC, Leenders AG, et al. Diagnostic investigations in individuals with mental retardation: a systematic literature review of their usefulness. Eur J Hum Genet 2005;13:6-25.

13 Dawson AJ, Putnam S, Schultz J, et al. Cryptic chromosome rearrangements detected by subtelomere assay in patients with mental retardation and dysmorphic features. Clin Genet 2002;62:488-94.

14 Flint J, Knight S. The use of telomere probes to investigate submicroscopic rearrangements associated with mental retardation. Curr Opin Genet Dev 2003;13:310-16

15 Knight SJ, Regan R, Nicod A, et al. Subtle chromosomal rearrangements in children with unexplained mental retardation. Lancet 1999;354:1676-81.

$16 \mathrm{Xu} \mathrm{J}$, Chen Z. Advances in molecular cytogenetics for the evaluation of mental retardation. Am J Med Genet C Semin Med Genet 2003;117:15-24.

17 Levi S. Ultrasound in prenatal diagnosis: polemics around routine ultrasound screening for second trimester fetal malformations. Prenat Diagn 2002;22:285-95.

18 Pop R, Conz C, Lindenberg KS, et al. Screening of the $1 \mathrm{Mb}$ SOX9 5' control region by array $\mathrm{CGH}$ identifies a large deletion in a case of campomelic dysplasia with XY sex reversal. J Med Genet 2004;41:e47.

19 Shaw CJ, Shaw CA, Yu W, et al. Comparative genomic hybridisation using a proximal 17p BAC/PAC array detects rearrangements responsible for four genomic disorders. J Med Genet 2004;41:113-19.

20 Van Buggenhout G, Melotte C, Dutta B, et al. Mild Wolf-Hirschhorn syndrome: micro-array $\mathrm{CGH}$ analysis of atypical $4 \mathrm{p} 16.3$ deletions enables refinement of the genotype-phenotype map. J Med Genet 2004;41:691-8.

21 Raven KA, Albertson DG, Pinkel D, et al. Additional patient with del(12)(q21.2q22) further evidence for a candidate region for cardio-faciocutaneous syndrome? Am J Med Genet 2002;110:51-6.

22 Weiss MM, Kuipers EJ, Postma C, et al. Genomic profiling of gastric cancer predicts lymph node status and survival. Oncogene 2003;22:1872-9.

23 Hansteen IL, Varslot K, Steen-Johnsen J, et al. Cytogenetic screening of a newborn population. Clin Genet 1982;21:309-14.

24 van Karnebeek CD, Koevoets C, Sluijter S, et al. Prospective screening for subtelomeric rearrangements in children with mental retardation of unknown aetiology: the Amsterdam experience. J Med Genet 2002;39:546-53.

25 Rossi E, Piccini $F$, Zollino $M$, et al. Cryptic telomeric rearrangements in subjects with mental retardation associated with dysmorphism and congenital malformations. J Med Genet 2001;38:417-20.

26 Riegel M, Baumer A, Jamar M, et al. Submicroscopic terminal deletions and duplications in retarded patients with unclassified malformation syndromes. Hum Genet 2001;109:286-94. 